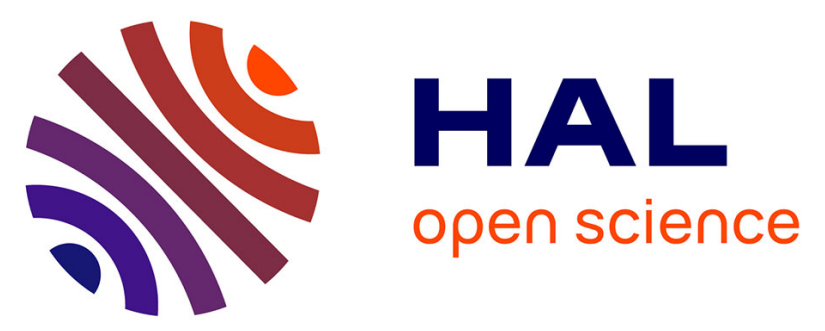

\title{
Classification of commercial skim milk powders according to heat treatment using factorial discriminant analysis of near-infrared reflectance spectra
}

\author{
G. Downey, P. Robert, D. Bertrand, P.M. Kelly
}

\section{- To cite this version:}

G. Downey, P. Robert, D. Bertrand, P.M. Kelly. Classification of commercial skim milk powders according to heat treatment using factorial discriminant analysis of near-infrared reflectance spectra. Applied Spectroscopy, 1990, 44 (1), pp.150-155. hal-02709730

\section{HAL Id: hal-02709730 \\ https: / hal.inrae.fr/hal-02709730}

Submitted on 1 Jun 2020

HAL is a multi-disciplinary open access archive for the deposit and dissemination of scientific research documents, whether they are published or not. The documents may come from teaching and research institutions in France or abroad, or from public or private research centers.
L'archive ouverte pluridisciplinaire HAL, est destinée au dépôt et à la diffusion de documents scientifiques de niveau recherche, publiés ou non, émanant des établissements d'enseignement et de recherche français ou étrangers, des laboratoires publics ou privés. 


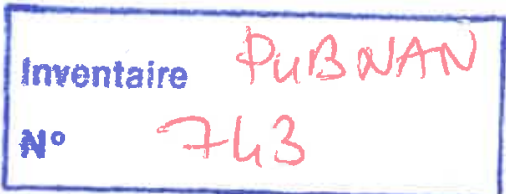

\title{
Classification of Commercial Skim Milk Powders According to Heat Treatment Using Factorial Discriminant Analysis of Near-Infrared Reflectance Spectra
}

\author{
G. DOWNEY, * P. ROBERT, \\ D. BERTRAND, and P. M. KELLY \\ Teagasc, The National Food Centre, Dunsinea, Cas \\ tleknock, Dublin 15, Republic of Ireland (G.D.); In- \\ stitut National de la Recherche Agronomique, LTAN \\ Rue de la Geraudiere, 44072 Nantes, Cedex 03, France \\ (P.R., D.B.); and Teagasc, National Dairy Product \\ Research Centre, Fermoy, Co. Cork, Republic of Ire- \\ land (P.M.K.)
}

Index Headings: Reflectance spectroscopy.

\section{INTRODUCTION}

Near-infrared reflectance (NIR) spectroscopy is well established as a rapid and nondestructive analytical technique in many agro-food industries. Most published applications have been concerned with the use of NIR for quantitative analyses of technologically important chemical constituents such as water ${ }^{1}$ and protein ${ }^{2}$ in grain, alcohol in wine, ${ }^{3}$ oil in mayonnaise, ${ }^{4}$ etc., although suc-

Received 29 June 1989.

* Author to whom correspondence should be sent. 
TABLE I. Summarized chemical data for milk powder samples.

\begin{tabular}{|c|c|c|c|c|c|c|c|c|}
\hline \multirow[b]{2}{*}{ Heat classification } & \multicolumn{2}{|c|}{$\%$ Total nitrogen } & \multicolumn{2}{|c|}{$\%$ Nonprotein nitrogen } & \multicolumn{2}{|c|}{$\%$ Noncasein nitrogen } & \multicolumn{2}{|c|}{$\%$ Whey protein nitrogen } \\
\hline & Mean & $\mathrm{SD}$ & Mean & $\mathrm{SD}$ & Mean & $\mathrm{SD}$ & Mean & SD \\
\hline $\begin{array}{l}\text { High heat } \\
\text { Medium heat }\end{array}$ & $\begin{array}{l}5.52 \\
5.52\end{array}$ & $\begin{array}{l}0.14 \\
0.27\end{array}$ & $\begin{array}{r}0.29 \\
0.30 \\
(0.31\end{array}$ & $\begin{array}{l}0.05 \\
0.07 \\
0.06)\end{array}$ & $\begin{array}{l}0.52 \\
0.78\end{array}$ & $\begin{array}{l}0.06 \\
0.25\end{array}$ & $\begin{array}{l}0.24 \\
0.49\end{array}$ & $\begin{array}{l}0.07 \\
0.22\end{array}$ \\
\hline Low heat & 5.33 & 0.11 & 0.24 & 0.04 & 1.12 & 0.10 & 0.88 & 0.12 \\
\hline
\end{tabular}

cesses have been reported with the prediction of less precisely defined but nonetheless functionally important sample attributes (e.g., wheat hardness ${ }^{5,6}$ ). A number of mathematical techniques have been used to develop accurate and stable prediction equations, among which may be mentioned stepwise multiple linear regression, principal component regression, partial least-squares regression, and derivative quotient mathematics.

In many cases, however, the problem faced in industry is not to accurately determine the content of one or more active constituents but rather to assign an unknown sample (raw material or finished product) to one of a number of functionally distinct groups. In such cases the task is to estimate the degree of similarity between the spectrum of an unknown sample and those typically found in whatever number of groups are relevant. Mark and Tunnel used Mahalanobis distances to categorize chemical products, while Bertrand et al., ${ }^{8}$ Devaux et al. ${ }^{9}$ and Dardenne and Biston ${ }^{10}$ have applied multiple discriminant analysis to the identification of wheat varieties. More recently, Devaux et al. ${ }^{11}$ have applied discriminant analysis to the factorial coordinates obtained following principal component analysis of near-infrared spectra. This approach has a number of advantages, among which may be mentioned the use of complete spectral data in the form of principal components to facilitate discrimination and the ability to extract graphical representations of discriminant functions ("discriminant spectral patterns"); these may permit some identification of the chemical groupings chosen statistically as the basis for discrimination.

Skim milk powder is quantitatively a very important product of the dairy industry: estimated worldwide production of this commodity in 1987 was $4.06 \mathrm{~m}$ tons. These powders may be manufactured with the use of a high-, medium-, or low-heat pretreatment of milk to produce three groups of powders which vary in a number of important functional properties-among which may be mentioned water-holding capacity. Current methods utilized by the dairy industry to confirm the heat classification of skim milk powders are tedious; methods commonly employed involve the estimation of undenatured whey protein by turbidimetry (following isoelectric coprecipitation of casein and complexed whey protein) ${ }^{12}$ and dye-binding techniques. ${ }^{13}$ The application of factorial discriminant analysis (FDA) to principal component scores obtained from NIR spectra of a representative set of skim milk powders was therefore attempted to see

TABLE II. Composition of sample sets in relation to heat treatment.

\begin{tabular}{lccccc}
\hline \multicolumn{1}{c}{ Sample set } & $\begin{array}{c}\text { High } \\
\text { heat }\end{array}$ & $\begin{array}{c}\text { Medium } \\
\text { heat }\end{array}$ & $\begin{array}{c}\text { Low } \\
\text { heat }\end{array}$ & Total \\
\hline Calibration development & 11 & 12 & 11 & 34 \\
Calibration evaluation & 10 & 13 & 9 & 32 \\
\hline
\end{tabular}

whether a simple and rapid classification procedure could be developed. Discriminant spectral patterns were produced in an attempt at identifying those molecular groups which were responsible for any discrimination achieved.

\section{EXPERIMENTAL}

Samples. Sixty-six samples of commercially produced skim milk powders were obtained from a number of creameries in the Republic of Ireland: 21 of these were classified by their creamery of origin as high-heat, 25 as medium-heat, and 20 as low-heat powders. Samples in each group were produced between June 1987 and October 1988 and came from more than one creamery. Each sample was analyzed for content of total nitrogen (TN) ${ }_{3}^{14}$ nonprotein nitrogen (NPN), ${ }^{15}$ noncasein nitrogen (NCN), ${ }^{16}$ and whey protein nitrogen (WPN); NPN was measured in reconstituted milks (10\% total solids). A summary of the results obtained by these analyses is shown in Table I. Moisture contents were not measured, but before the NIR spectra were recorded, all the samples were left open to the atmosphere for $48 \mathrm{~h}$. During this time and immediately prior to spectral analysis, each sample was thoroughly mixed: some samples tended to form aggregates, but these were easily destroyed by light manual pressure.

In order to facilitate discrimination between the three groups of milk powders, a new variable called "class" was

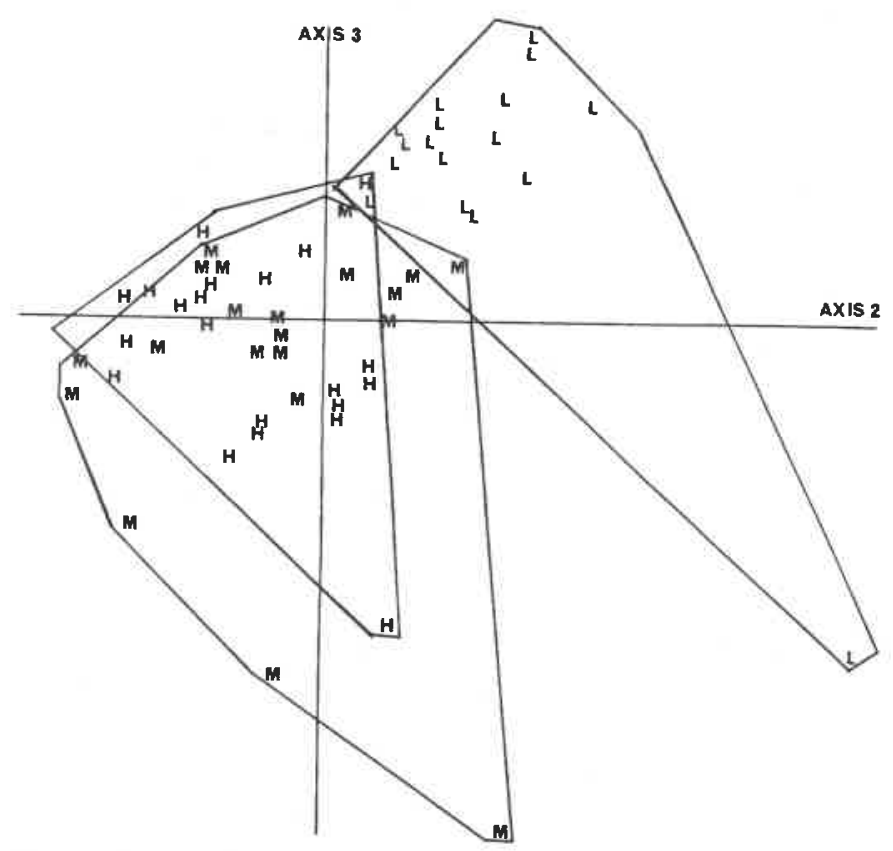

Fig. 1. Principal component scores for milk prediction samples on axes 2 and $3 ; \mathrm{L}=$ low-heat, $\mathrm{M}=$ medium-heat, and $\mathrm{H}=$ high-heat 


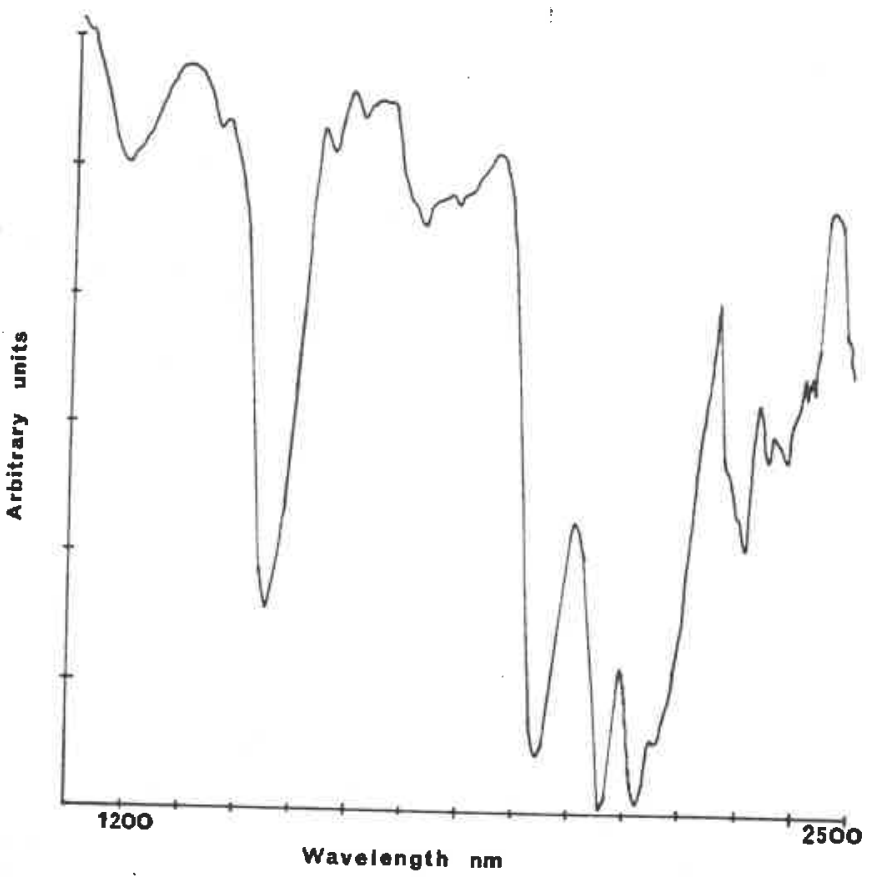

FIG. 2. Spectral pattern of principal component 2.

created; low-heat samples were arbitrarily ascribed a value of 1 , medium-heat samples a value of 2 , and high-heat samples the value 3 .

The sample collection was divided into a calibration development set (34 samples) and a prediction set (32 samples); the composition of these sets in terms of powder heat-treatment is shown in Table II.

Spectral Measurements. Spectra were recorded with a Technicon InfraAlyzer $500 \mathrm{C}$ in the range of 1100 to 2500 $\mathrm{nm}$ at $4-\mathrm{nm}$ intervals (351 data points per spectrum). Each recorded spectrum was the mean of two scans on one sample (i.e., with no re-packing of the sample cup). Data were collected on an HP1000L computer and transferred to an IBM-PC for data manipulation using programs written by the staff of the INRA laboratory.

Data Treatments. All spectra were normalized in order to minimize particle size effects by reducing the area under each spectrum to a value of 1 according to the
formula

$(\log 1 / R)_{i \text { normalized }}$

$$
=(\log 1 / R)_{i} / \sqrt{\sum_{i=1}^{i=351}(\log 1 / R)_{i}{ }^{2}}
$$

where $(\log 1 / R)_{i}$ is the absorbance recorded at wavelength $i$.

Principal component analysis was applied to the normalized spectral data with the use of wavelengths as principal variables and "class" values as supplementary variables; calibration samples and prediction samples were principal and supplementary observations, respectively. PC space was created with the use of principal observations and variables.

Factorial discriminant analysis was performed on the PC scores, the mathematical processing being simplified as required. As previously outlined, ${ }^{11}$ this procedure is equivalent to a principal component analysis of the grav-
TABLE III. Assignment of main features of principal component 2 .

\begin{tabular}{cl}
\hline Spectral feature & \multicolumn{1}{c}{ Assignment } \\
\hline $1200 \mathrm{~nm}$, trough & CH stretch, 2nd overtone \\
$1300 \mathrm{~nm}$, peak & $?$ \\
$1452 \mathrm{~nm}$, trough & OH stretch, 1st overtone \\
$1724 \mathrm{~nm}$, trough & CH stretch, 1st overtone \\
$1788 \mathrm{~nm}$, trough & CH stretch, 1st overtone \\
$1864 \mathrm{~nm}$, peak & $?$ \\
$1940 \mathrm{~nm}$, trough & OH stretch + OH deformation \\
$2004 \mathrm{~nm}$, peak & NH sym. str. + amide II \\
$2056 \mathrm{~nm}$, trough & NH sym. str. + amide II \\
$2088 \mathrm{~nm}$, peak & OH str. + OH deformation \\
$2124 \mathrm{~nm}$, trough & NH sym. str. + amide III \\
$2152 \mathrm{~nm}$, peak & Amide I + amide II \\
$2308 \mathrm{~nm}$, trough & CH str. + CH deformation \\
\hline
\end{tabular}

Taken from Refs. 17 and 18.

ity centers of each group, calculated on the normalized PC scores. Gravity centers are principal observations, and the original samples are supplementary ones.

\section{RESULTS}

Principal Component Analysis. Twenty principal components were developed, with the first 5 explaining $99 \%$ of the total variance of the variables input into the analysis. Individual components contributed as follows: $\mathrm{PC1}$, 72.1\%; PC2, 14\%; PC3, 8.6\%; PC4, 2.8\%; PC5, $1.5 \%$. The five principal components most highly correlated to "class" were PC2 $(r=0.62)$, PC3 $(r=0.38)$, PC9 ( $r=$ $0.33), \operatorname{PC} 7(r=0.21)$, and PC6 $(r=0.20)$. The number of components involved and the magnitude of their associated correlation coefficients suggested that principal component analysis, while able to model the variable "class," would be unable to completely discriminate between values of this variable. To confirm this visually, we plotted the factorial coordinates obtained for each of the 66 samples using principal components 2 and 3 as abscissa and ordinate, respectively. In this diagram (Fig. 1), milk powder samples have been almost separated into two groups along the abscissa, i.e., on the basis of $\mathrm{PC2}$. While the medium $(\mathrm{M})$ and high $(\mathrm{H})$ heat samples are completely overlapping, there is only a very slight confusion between these groups and the low (L) heat powders. PC3 appears to contribute to some polarization of the cloud containing medium $(M)$ and high $(H)$ heat samples. Thus, with these two principal components alone, it is possible to distinguish the low (L) heat samples from the others with almost complete certainty.

In order to gain some insight into the biochemical reason for the observed discrimination, the spectral pattern of principal component 2 was drawn. The spectral

TABLE IV. Values of the two discriminant factor elements.

\begin{tabular}{ccc}
\hline PCA scores & Factor 1 & Factor 2 \\
\hline 1 & 0.1525 & -0.0389 \\
2 & 0.6769 & 0.2860 \\
3 & 0.5266 & 0.0557 \\
4 & 0.0395 & 0.2766 \\
5 & 0.1430 & 0.0707 \\
6 & 0.2682 & -0.6037 \\
7 & 0.0794 & 0.2554 \\
8 & -0.2209 & 0.3175 \\
9 & 0.0033 & -0.5432 \\
13 & 0.3037 & -0.0810 \\
\hline
\end{tabular}


TABLE V. Classification table for milk powder samples.

\begin{tabular}{ccrrr} 
& & L & M & H \\
\hline Calibration development & L & 11 & 0 & 0 \\
sample set & M & 0 & 12 & 0 \\
Prediction sample set & H & 0 & 0 & 11 \\
& L & 9 & 0 & 0 \\
& M & 0 & 10 & 3 \\
& H & 0 & 0 & 10 \\
\hline
\end{tabular}

pattern is the eigenvector of each principal component axis, and the curve obtained is shown in Fig. 2. Principal component 2 contributed significantly to the separation between $L$ and $(M+H)$ samples, and the main structural assignments of this spectral pattern are listed in Table III. An examination of this pattern reveals the importance of water and protein groups in achieving the observed discrimination. Given that milk powders are generally manufactured to a specified moisture content (normally $3.5 \%$ ) and that precautions were taken to minimize any between-sample differences in moisture, principal component 2 may be estimating water in some particular state. In this context, not all of the moisture in dried milk is extractable with the use of oven-drying
methods. ${ }^{19}$

The involvement of absorptions linked to protein groups is consistent with the fact that the heat classification system for skim milk powders is a reflection of the extent of whey protein denaturation which takes place during the variable pre-heat treatments. Such denaturation involves the oxidation of -SH groups and disulphide (-S-S-) interchange reactions; in this context it may be of some relevance to note the reported ${ }^{17}$ position of a first overtone S-H stretch vibration at $1740 \mathrm{~nm}$ and the presence of some maxima in this spectral region (Fig.
2)

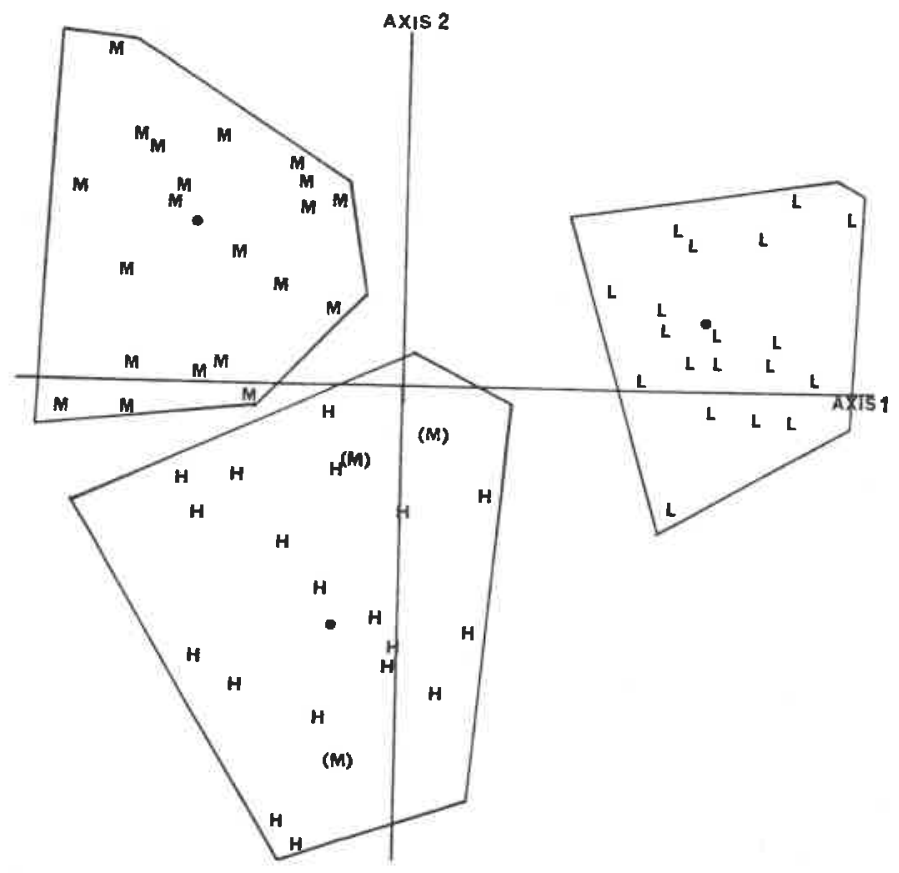

FIG. 3. Discriminant map of milk prediction samples. Samples in parentheses are wrongly classified; (ध) represents the gravity centers
of each group.

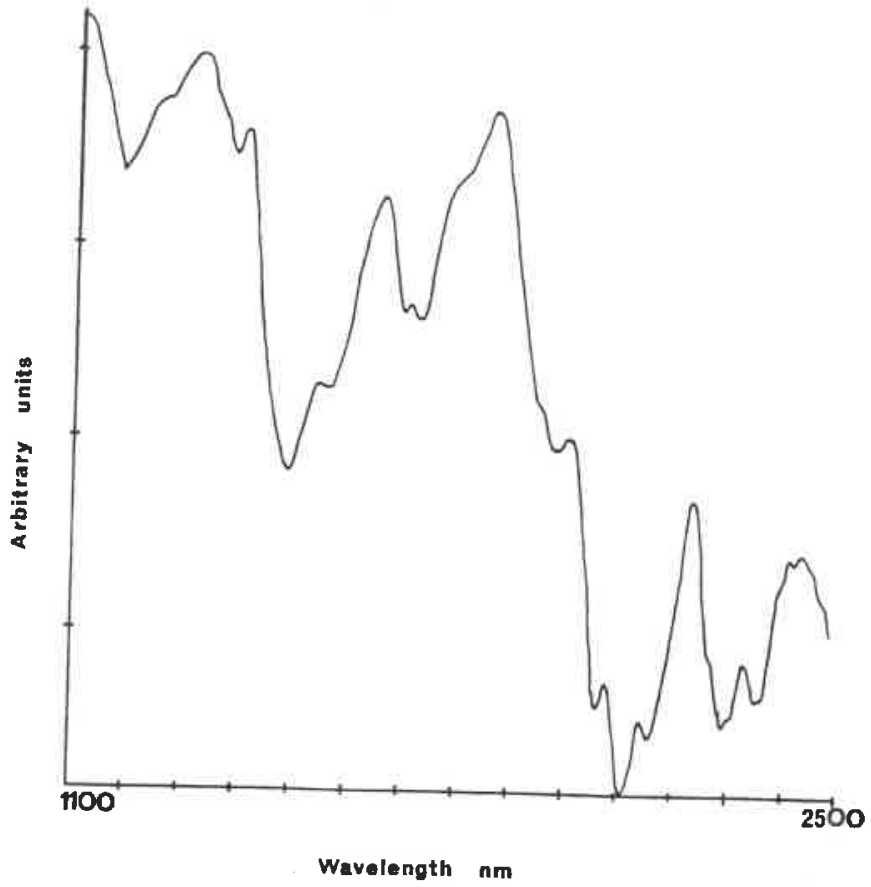

FIG. 4. Spectral pattern of discriminant factor 1.

Meaningful interpretation of the more complex and less significant principal component 3 was not possible.

Factorial Discriminant Analysis. In the first stage of this procedure, 20 principal components were input into a stepwise discriminant procedure to identify those components that would discriminate the samples into 3 groups. Ten components were needed to correctly classify all samples in the calibration development set; $91 \%$ of those in the evaluation set were correctly identified. These 10 components (PCs 1-9, 13) were input into a factorial discriminant procedure to generate two functions which produced almost perfect discrimination between all three sample groups. The first discriminant function explained $55.1 \%$ of the variance input, with the second accounting for $44.9 \%$ - this compares well with the theoretically perfect apportionment of $50 \%$ in each case. Those principal components which were highly correlated with discriminant function 1 were PC1 $(r=0.97)$ PC2 $(r=0.93)$, PC3 $(r=0.99)$, PC5 $(r=0.91)$, PC8 $(r$ $=-0.61)$, and PC13 $(r=0.97)$; corresponding components for the second function were PC4 $(r=-0.99)$, PC6 $(r=-0.90)$, PC7 $(r=0.95)$, PC8 $(r=0.79)$, and PC9 $(r$ $=-1.0)$. Discriminant factor 1 gave most weight to principal component scores 2 and 3 , while for the second function, scores 6 and 9 were of greatest importance (see Table IV).

Percentage correct classification rates for the calibration development and evaluation sample sets were as achieved above. Of the 32 samples in the prediction set, all 10 of class $3(\mathrm{H})$ and all 9 of group $1(\mathrm{~L})$ were correctly classified. Three of the 13 samples in group $2(\mathrm{M})$ were incorrectly classified as belonging to group 3 (Table V). The separation achieved may be seen in Fig. 3 , in which the incorrectly classified samples are clearly marked. Thus, discriminant function 1 is separating the samples in group $1(\mathrm{~L})$ from the others, while function 2 effects the discrimination between groups $2(M)$ and $3(\mathrm{H})$. Some 


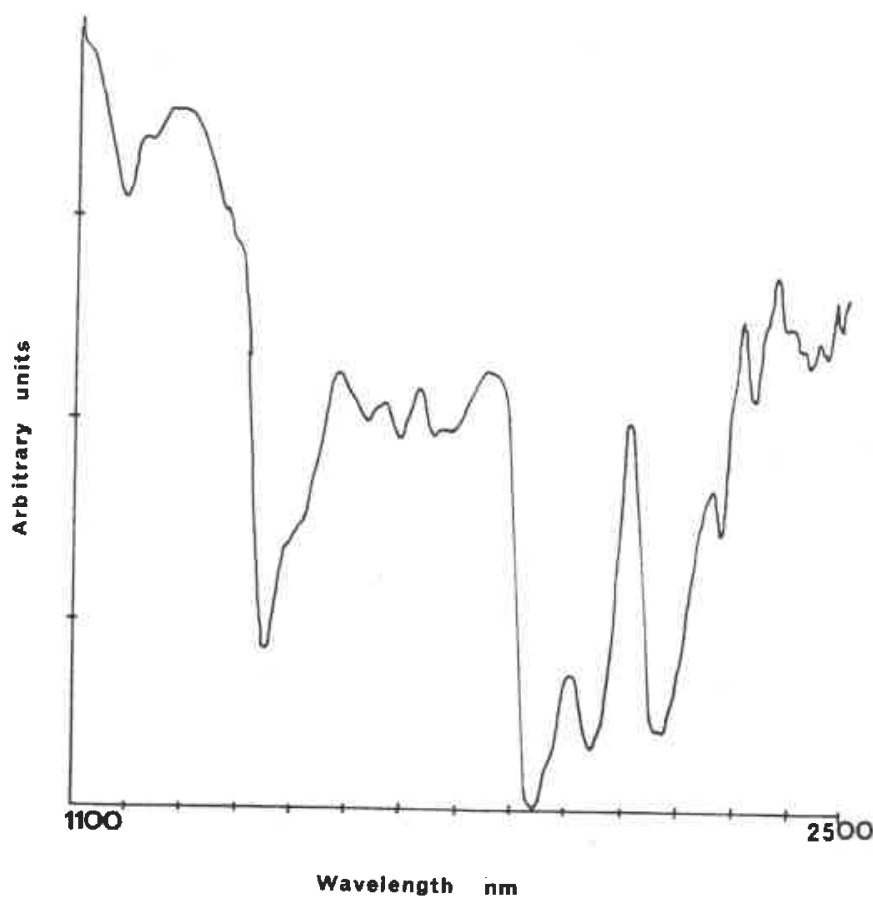

FIG. 5. Spectral pattern of discriminant factor 2.

misclassification of medium heat samples is not unexpected in any three-way system; in this case, particular difficulties arise from the somewhat arbitrary definition of the heat-treatment classes, with certain processing plants further dividing the medium group into mediumhigh and medium-low subgroups. In such cases, classification difficulties may also be experienced with the existing chemical procedures.

In order to understand the basis for the observed separation, the patterns of these discriminant functions were drawn and examined (Figs. 4 and 5). With regard to discriminant pattern 1 , the major features and their tentative assignments are shown in Table VI. It can be seen that many correspond to molecular vibrations commonly associated with protein groups, although vibrations arising from $-\mathrm{OH}$ groups are also present (1408 and 2080 $\mathrm{nm})$. In similar fashion, an examination of the significant features of discriminant function 2 has been performed (Table VI). This spectral pattern resembles the profile of eigenvector 2 . In this case, absorptions at 1448 and $1936 \mathrm{~nm}$ suggest the extraction of some information about water, while most of the other absorption maxima and minima may be attributed to protein groups. Absorptions in the region 1600 to 1800 are normally ascribed to $\mathrm{CH}$ band vibrations, as are those above $2300 \mathrm{~nm}$ as well.

Attenuated Spectral Data. With the use of complete spectra, it has been possible to achieve a high level of certainty in classifying commercial skim milk powders in accordance with their heat treatment. In industry, however, the most commonly used NIR instrumentation only measures reflectance at a limited number of wavelengths. One of the most widely used such instruments is the Technicon $400 / 450$ series, which collects data at 19 wavelengths only. In order to investigate the immediate utility of the results reported here, the data treatments were repeated with only reflectance measurements obtained at the center wavelengths of the 19 filters stan-
TABLE VI. Assignment of main features of the spectral pattern of discriminant functions 1 and $2 .{ }^{a}$

\begin{tabular}{|c|c|c|c|}
\hline \multicolumn{2}{|r|}{ Function 1} & \multicolumn{2}{|r|}{ Function 2} \\
\hline $\begin{array}{l}\text { Spectral } \\
\text { feature }\end{array}$ & Assignment & $\begin{array}{l}\text { Spectral } \\
\text { feature }\end{array}$ & Assignment \\
\hline $\begin{array}{l}1188 \mathrm{~nm} \\
1492 \mathrm{~nm}\end{array}$ & $\begin{array}{l}\mathrm{CH}, \text { 2nd overtone } \\
\mathrm{NH}, \text { 1st overtone }\end{array}$ & $\begin{array}{l}1184 \mathrm{~nm} \\
1448 \mathrm{~nm}\end{array}$ & $\begin{array}{l}\mathrm{CH}, \text { 2nd overtone } \\
\mathrm{OH}, \text { 1st overtone }\end{array}$ \\
\hline $1564 \mathrm{~nm}$ & $\begin{array}{l}\mathrm{OH} \text { or } \mathrm{NH}, 1 \text { st } \\
\text { overtone }\end{array}$ & $1936 \mathrm{~nm}$ & $\mathrm{OH}$ str. + OH def. \\
\hline $\begin{array}{l}1980 \mathrm{~nm} \\
2050 \mathrm{~nm}\end{array}$ & NH + amide II & $2040 \mathrm{~nm}$ & $\begin{array}{l}\mathrm{C}=\mathrm{O} \text { 2nd overtone } \\
\text { or } \mathrm{NH}+\text { amide } \mathrm{II}\end{array}$ \\
\hline $\begin{array}{l}2108 \mathrm{~nm} \\
2160 \mathrm{~nm}\end{array}$ & $\begin{array}{l}\mathrm{NH}+\text { amide III } \\
\text { Amide I + amide III }\end{array}$ & $2168 \mathrm{~nm}$ & Amide I + amide III \\
\hline
\end{tabular}

a Taken from Ref. 17.

dard in the InfraAlyzer 400/450 research instrument. As was found above, separation of the low-heat (L) samples was possible with the first discriminant function, but even the use of the first 10 principal components did not permit a clear separation of medium- $(\mathbf{M})$ and high- $(\mathrm{H})$ heat samples; indeed, the calibration development set of samples could not be completely correctly classified with this reduced spectral information.

\section{CONCLUSIONS}

Reflectance measurements in the near-infrared spectral region are highly intercorrelated; $P C$ analysis removes this intercorrelation by the creation of new variables (principal components). Thus the application of factorial discriminant analysis on principal components should be more efficient than its use with reflectance data. The potential of this approach has previously been reported with the use of a model data set; ${ }^{11}$ in this work, a set of commercial milk powder samples has been subjected to the same data processing in order to establish whether the principles thus established would work successfully on a real problem. It can be seen that almost complete success has been achieved in the classification of this small group of samples, enough to warrant a more exhaustive study using a larger sample set. The use of graphical illustrations has been helpful in suggesting a molecular basis for the discrimination achieved. It was not possible to obtain correct classification of the samples when spectral data at only 19 wavelengths were used, thus restricting the application of this technique in this instance to monochromator instruments.

\section{ACKNOWLEDGMENTS}

G. Downey wishes to acknowledge the technical assistance of Ms. Maura Bourke (Teagasc), for chemical analysis of the samples, and the staff of INRA, for assistance and encouragement. This work was carried out at Nantes with the support of the EEC Stimulation Program (GD).

1. G. Downey, J. Sci. Food Agric. 36, 951 (1985).

2. P. C. Williams, Cereal Chem. 52, 561 (1975).

3. F. Altmeyer, Monatsschr. Brau. 37, 88 (1984).

4. A. M. C. Davies and T. F. Brocklehurst, J. Sci. Food Agric. 37, 310

5. H. Zwingelberg, Getreide Mehl Brot 37, 25 (1983)

6. B. G. Osborne and T. Fearn, J. Sci. Food Agric. 34, 1011 (1983).

7. H. L. Mark and D. Tunnell, Anal. Chem. 57, 1449 (1985). (1985). 
9. M. F. Devaux, D. Bertrand, and G. Martin, Cereal Chem. 63, 151 (1986).

10. P. Dardenne and R. Biston, "Attempt to Recognize Wheat Species by Discriminant Analysis," presented at the International NIR/T Spectroscopy Conference, Budapest, Hungary (1986).

11. M. F. Devaux, D. Bertrand, P. Robert, and M. Qannari, Appl Spectrosc. 42, 1015 (1988).

12. Standards for Grades of Dry Milks (American Dry Milk Institute, Chicago, nlinois, 1965).

13. T. C. A. McGann, J. A. O'Connell, and R. McFeely, J. Soc. Dairy Technol. 28, 23 (1975).

14. International Dairy Federation Standard Method 20A (1986),

15. J. A. Phelan, A. M. O'Keeffe, M. K. Keogh, and P. M. Kelly, Irish J. Fd. Sci. Technol. 6, 1 (1982).

16. International Dairy Federation Standard Method 29 (1964).

17. B. G. Osborne and T. Fearn, Near Infrared Spectroscopy in Food Analysis (Longman Scientific and Technical, Harlow, Essex, England, 1986), Chap. 2, pp. 36-40.

18. P. C. Williams and K. Norris, Near Infrared Technology in the Agricultural and Food Industries (AACC, St. Paul, Minnesota, 1987), Chap. 15, p. 246.

19. P. M. Kelly, personal communication. 